\title{
PEMBACAAN HEURISTIK DAN HERMENEUTIK PUISI INDONESIA MODERN BERTEMA PEWAYANGAN
}

\author{
Dian Hartati \\ Fakultas Keguruan dan Ilmu Pendidikan, Universitas Singaperbangsa Karawang \\ dian.hartati@fkip.unsika.ac.id
}

\begin{abstract}
Abstrak
Perkembangan puisi modern Indonesia tidak terlepas dari kebudayaan yang telah mengakar. Salah satu sumber penciptaan puisi yang diusung penyair berasal dari kisah-kisah pewayangan. Pembacaan heuristik dan hermeneutik perlu dilakukan agar makna puisi dapat diterima pembaca dengan baik. Mengingat kisah-kisah pewayangan hanya diketahui kelompok masyarakat tertentu. Metode penelitian yang digunakan adalah metode kualitatif. Hasil penelitian dipaparkan secara deskriptif. Analisis puisi menggunakan pembacaan heuristik dan pembacaan hermeneutik Michael Riffaterre. Data yang digunakan adalah puisi "Sita Sihir" karya Sapardi Djoko Damono, puisi "Hikayat Sri Rama" karya Goenawan Mohamad, dan puisi "Penyesalan Kunti" karya Djoko Saryono. Hasil pembacaan merujuk pada pemaknaan nilai-nilai yang humanis.
\end{abstract}

Kata Kunci: puisi, pembacaan heuristik, pembacaan hermeneutik.

\begin{abstract}
The development of modern Indonesian poetry is inseparable from deeply rooted culture. One of the sources of poetry creation carried by poets comes from puppet stories. Heuristic and hermeneutic read needs to be done, so the meaning of poetry reader to be acceptable. Given that puppet stories are only knowling to certain community groups. The research method used is a qualitative method. The results of the study were present the descriptiv. Poetry analysis uses heuristic read and hermeneutic of Michael Riffaterre. The data used is the poem "Sita Sihir" by Sapardi Djoko Damono, the poem "Hikayat Sri Rama" by Goenawan Mohamad, and the poem "Penyesalan Kunti" by Djoko Saryono. The results of the reading refer to the meaning of humanistic values.
\end{abstract}

Keywords: poem, the read heuristic, the read hermeneutic

\section{PENDAHULUAN}

Kisah pewayangan muncul pertama kali sejak ajaran Hindu bersamaan dengan datangnya kebudayaan India yang masuk ke di Indonesia. Setelah ajaran Islam berkembang, wayang dianggap sebagai cerminan kehidupan dan memberikan nilai-nilai pendidikan moral yang tinggi. Sejarah wayang dalam bentuknya yang asli timbul sebelum kebudayaan Hindu masuk ke Indonesia dan mulai berkembang pada zaman Hindu Jawa. Zaman Hindu menjadi salah satu zaman di mana wayang dicoba untuk dikembangkan sedemikian rupa, sehingga wayang pada waktu itu disenangi sebagai bentuk falsafah, pelajaran penting yang bisa dianut dalam kehidupan (Ra'uf, 2010: 22).

Berdasarkan paparan tersebut maka kisah pewayangan memiliki makna yang kuat. Dengan kata lain tokoh-tokoh wayang memiliki posisi 
dalam benak manusia. Kehadirannya menjadi salah satu sumber gagasan bagi penyair Indonesia modern. Tema-tema lokal digali guna menyegarkan puisipuisi yang berkiblat ke barat. Salah satu tema lokal yang diangkat adalah kisah pewayangan yang selama ini dikenal masyarakat Jawa. Umar Kayam (dalam Zaidan, 2002: 9) menegaskan bahwa bagi orang Jawa, wayang merupakan sumber rujukan untuk memahami peristiwa yang terjadi dan akan terjadi.

Kisah-kisah pewayangan dipilih dari sekian banyak tema dan dihadirkan dengan beragam tafsir. Ada yang mempertahankan kisah atau bahkan menjungkirbalikkan kisah sesuai interpretasi masing-masing penyair. Pengadaptasian kisah-kisah pewayangan dalam perpuisian Indonesia modern tentu saja menciptakan makna baru.

Salah satu cara untuk mendapatkan pemaknaan tersebut dengan melakukan pembacaan puisi secara heuristik dan heurmeneutik. Pembacaan heuristik dan pembacaan heurmeneutik merupakan bagian dari semiotik yang digagas Riffatere dalam Semiotic of Peotry. Pembacaan heuristik, pada dasarnya, merupakan interpretasi tahap pertama, yang bergerak dari awal ke akhir teks sastra, dari atas ke bawah mengikuti rangkaian sintagmatik (Ratih, 2016: 6).

Pembacaan hermeneutik adalah pembacaan yang didasarkan pada konvensi sastra. Kata-kata yang semula tidak gramatikal menjadi himpunan kata-kata ekuivalen, maksudnya adalah pembacaan yang bermuara pada ditemukannya satuan makna puisi secara utuh dan terpadu. Puisi harus dipahami sebagai sebuah satuan yang bersifat struktural atau bangunan yang tersusun dari berbagai unsur kebahasaan. Pembacaan dilakukan bolak-balik dari suatu bagian ke keseluruhan dan kembali ke bagian yang lain dan seterusnya.

Menurut Endraswara (2013: 42)

secara sederhana hermeneutik berarti tafsir, sedangkan menurut Ricouer hermeneutik adalah acara memahami makna sastra yang ada di balik struktur. Pemahaman makna, tak hanya pada simbol, melainkan memandang sastra sebagai teks.

\section{METODE PENELITIAN}

Metode penelitian yang digunakan adalah metode kualitatif. Metode penelitian (Sugiyono, 2014: 2) pada dasarnya merupakan cara ilmiah untuk mendapatkan data dengan tujuan dan kegunaan tertentu. Sumber data utama pada penelitian kualitatif ialah kata-kata, dan tindakan, selebihnya adalah data tambahan seperti dokumen dan lain-lain (Moleong: 2010). Hasil penelitian akan dipaparkan secara deskriptif berdasarkan temuan yang didapatkan setelah data dianalisis. Menurut Ratna (2004: 53) metode analisis deskriptif adalah metode yang digunakan dengan cara menganalisis dan menguraikan untuk menggambarkan keadaan objek yang diteliti yang dijadikan pusat perhatian dalam menggambarkan penelitian.

Dari penelusuran literatur (di antaranya: Teeuw, 1989; Nurgiyantoro, 1998; Nurgiyantoro, 2003; Danardana, 2013) ditemukan penyair-penyair yang menulis puisi tertema kisah pewayangan sebagai berikut.

1. Angkatan Balai Pustaka penyair Sanusi Pane menulis puisi berjudul "Arjuna", "Kepada Krisna", dan "Wijaya Kesuma".

2. Angkatan Pujangga Baru penyair Armijn Pane yang menulis puisi berjudul "Panggilan Krisna".

3. Periode 1953-1961 penyair Subagio Sastrowardojo menulis puisi "Parasu Rama", "Kayon", 
"Garuda", "Wayang", "Bima", "Matiya Pandawa yang Saleh", "Kayal Arjuna", "Dalang", "Asmaradana", dan "Batara Kala"; Sapardi Djoko Damono menulis "Di Banjar Tunjuk, Tabanan", "Setengah Kenangan", "Pesan", "Telinga", "Benih", dan "Sita Sihir".

4. Angkatan 66 penyair Goenawan Muhammad menulis "Parikesit", "Asmaradana"; Darmanto Jt. Menulis "Hal-hal yang Mokal dan Lokan-okal Badrayana Lawan Narada".

5. Periode 1970-1980-an terdapat penyair-penyair seperti Linus Suryadi AG menulis "Bonowati dan Limbuk", "Abimanyu di Padang Kurusetra", "Duryudana dan Durna", "Pengakuan Kunti Talibrata", "Himbauan Cangik", "Petruk Kumat"; Saini KM menulis "Dewa Ruci"; Nyoman Tusthi Eddy menulis puisi "Brahma dan Nilotama"; Heru Emka menulis "Asmaradana", Bambang Sarwono menulis puisi "Wibisono", "Suprobo", "Arjuna", Yudisthira ANM Massardi menulis puisi "Di Beranda ini, Mohamad Pariksit, Telah jadi Logam", Suminto A. Sayuti dengan puisi "Genderang Kurusetra", Bambang Suryanto dengan judul puisi "Cinta Pertama", Isma Sawitri menulis "Pesona Kurusetra"; Dorothea Rosa Herliany menulis puisi berjudul "Elegi Sinta"; Soni Farid Maulana menulis "Sita Obong".

6. Periode 2000-an terdapat penyairpenyair seperti Setiyo Bardono menulis "Kelahiran Kurawa", "Sayap Kejujuran Yudistira", Gunawan Maryanto menulis "Surtikanti", "Banowati", "Aswatama", "Gandari Memasuki Kegelapan", "Gandari di Puncak
Kegelapan"; Triyanto Triwikromo menulis puisi "Sumpah Drupadi", "Semar Sungsang", "Hikayat Togog", "Pembakaran Sinta"; Djoko Saryono puisi berjudul "Perasaan Hati Wibisana" dan "Penyesalan Kunti"; Edwar Maulana menulis "Madrim" dan "Dasamuka", dan Adimas Imanuel menulis "Sembrada" dan "Jatayu".

Berdasarkan penelusuran tersebut, hasil analisis pembacaan heuristik dan hermeneutik yang akan disajikan adalah Puisi "Sita Sihir" Karya Sapardi Djoko Damono (Grasindo, 2004), Puisi "Hikayat Sri Rama" Karya Goenawan Mohamad (Tempo, 2013), dan Puisi "Penyesalan Kunti" Karya Djoko Saryono (Aditya Media Publishing, 2013).

\section{HASIL DAN PEMBAHASAN}

Kesusastraan Indonesia modern (Teeuw, 1980: 15) lahir pada sekitar tahun 1920. Ketika itulah para pemuda Indonesia untuk pertama kali mulai menyatakan perasaan dan ide yang pada dasarnya berbeda daripada perasaan dan ide yang terdapat dalam masyarakat setempat yang tradisional dan mulai berbuat demikian dalam bentuk-bentuk sastra Melayu, Jawa, dan sastra lainnya yang lebih tua, baik lisan maupun tulisan.

Puisi modern Indonesia mengalami perubahan tema dalam setiap periode. Pada periode awal kemunculannya, tema-tema yang ditulis penyair di antaranya perjuangan untuk persatuan dan mencapai kemerdekaan, keagamaan, sosial, kritik sosial, personal, nasihat, alam dan lingkungannya (Mahmud, 2011: 41-50). Kehadiran tema-tema tersebut berhubungan dengan situasi negara, peristiwa Sumpah Pemuda, dan keberanian-keberanian dalam hal 
mengungkapkan pengakuan rasa cinta terhadap tanah air.

Pembacaan Heuristik Puisi "Sita Sihir" Karya Sapardi Djoko Damono

Terbebas juga akhirnya aku entah dari cakar Garuda atau lengan Dasamuka (yang begitu kuat.) (Aku) Sendiri(an), di menara tinggi (dan) kusaksikan di atas: Langit yang tak luntur dingin-birunya; dan di bawah (sana): (aku lihat) api yang disulut Rama - (api itu) berkobar bagai rindu $\operatorname{abadi}($.

"Terjunlah, Sita," bentak-Mu, "agar udara, air, api, dan tanah, kembali murni."

(Aku pasrah,) Tapi (sebenarnya) aku ingin juga terbebas dari sihir Rama (yang selama ini mengekangku).

\section{Pembacaan Hermeneutik Puisi "Sita Sihir" Karya Sapardi Djoko Damono}

Sita telah terbebas dari perjumpaannya dengan seekor burung Garuda. Sita merasa dirinya dimatamatai oleh burung suruhan suaminya. Baru saja terlepas dari Garuda, Sita jatuh ke tangan Dasamuka. Pemimpin raksasa yang terkenal kejam itu menyekap Sita. Dengan usaha keras, Sita berusaha lepas dari kurungan Dasamuka. Usaha Sita tidak sia-sia. Dia bebas dari segala ketakutan yang diciptakan Rahwana.

Takdir buruk masih saja mengikuti Sita setelah lepas dari cengkeraman Dasamuka. Dia diminta Rama, suaminya, terjun ke kobaran api untuk memurnikan alam semesta. Udara, air, api, dan tanah harus suci kembali. Sinta pun harus dalam keadaan suci setelah tinggal bersama Dasamuka. Mau tak mau Sita mengikuti perintah suaminya. Dia harus masuk ke kobaran api yang telah disediakan Rama.

Tapi, sebenarnya yang ingin dilakukan Sita adalah pergi meninggalkan Rama. Sita ingin lepas dari segala cengkeraman Rama bahkan melupakan cinta yang pernah ada di antara mereka.

\section{Makna Puisi "Sita Sihir" Karya Sapardi Djoko Damono}

Setelah terbebas dari kekuasaan Dasamuka, Sita harus menjalani upacara bakar diri untuk membuktikan kesuciannya. Penyataan tokoh Sita dalam teks puisi yang ingin terbebas dari pengaruh Rama diungkapkan dengan sangat tegas. Tokoh Sita dalam puisi "Sita Sihir" bertentangan dengan kisah pewayangan.

"Sihir" yang bermakna kekuatan gaib menjadi simbol bagi Sita bahwa dirinya telah terpesona, telah terpikat, dan akan selalu mengikuti kemauan Rama, salah satunya menuruti keinginan Rama mengadakan upacara bakar diri. Sita merasa kepercayaan Rama sebagai suami telah berkurang dan karenanya Sita ingin terbebas dari sosok yang tidak mempercayainya lagi.

\section{Pembacaan Heuristik Puisi "Hikayat Sri Rama" Karya Goenawan Mohamad}

Di dalam puisi "Hikayat Sri Rama" terdapat lima fragmen. Fragmen pertama berjudul Kumbakarna, fragmen kedua Trijatha kepada Kapi Jembawan, fragmen ketiga berjudul Sugriwa, fragmen keempat berjudul Sita, fragmen kelima berjudul Epilog. Fragmen pertama terdiri atas 35 larik, fragmen kedua terdiri atas 36 larik, fragmen ketiga terdiri atas 26 larik, fragmen keempat terdiri atas 8 larik, dan fragmen terdiri atas 30 larik, sehingga keseluruhan larik berjumlah 135. Keseluruhan larik merupakan kesatuan yang padu, walau begitu fragmenfragmen tersebut dapat berdiri sendiri jika puisi dibacakan secara terpisah. 


\section{Fragmen Kesatu}

Ayah itu bercerita tentang seorang penidur yang sakti, (juga) seorang tambun yang bertapa di bukit, (dia) yang (suka) mendengkur dan ingin bermimpi tentang negeri yang tak punya raja.

"(D)Ia bernama Kumbakarna." (ucap ayah.) Anaknya hanya memahat kayu, (dan) mungkin separuh mendengarkan (cerita sang ayah). (D)Ia (Si Anak) tahu cerita itu akan berakhir dengan kematian; (d)ia ingin pahat itu tak melukai tubuh ikan yang dibentuknya (dengan hati-hati), karena (ke)sedih(an) akan jadi panjang dan umur (ia merasa begitu) hanya pendek.

"Aku menunggumu, Alengka, di jalan yang tak mudah,' kata Kumbakarna sebelum berangkat." (Kumbakarna pergi.) "Meninggalkan tujuh pengawal yang menemaninya, si tambun (itu) pun menyeberangi bentangan hutan. Dan sejak pagi itu, di Alengka semua berhenti. Kata-kata, selalu dimaksudkan, selalu didesakkan, berubah seperti defile prajurit yang berputar(-putar). (Seolah) Tak ada lagi garis depan."

'Esoknya, dari tepi selat, orang (-orang) melihat sepasukan makhluk (kera) aneh melintasi laut. Hanya samar. (Ada) Kabut membentuk berpuluhpuluh cerita. (Dan) Seorang pengintai mengatakan ada musuh datang dari (kerajaan) Kiskenda, tapi (sebenarnya) tak ada yang tahu benarkah ada negeri (bernama) Kiskenda."

'Kumbakarna berbisik, "tidak", (menoleh ke belakang) dan (d)ia pergi ke lekuk bukit.' (jauh di sana).

Di luar cerita, anak itu (terus) meraut sirip dan membayangkan arus yang biru gelap, (dalam bayangan itu) di mana tak ada yang tak bergerak, $(\mathrm{Si}$ Anak khawatir pada waktu) juga kematian.
Ayahnya ( $\mathrm{Si}$ Anak) pun menutup ceritanya, (dengan) lelah: 'Di jalan yang tak mudah, (sosok) Kumbakarna bermimpi tentang sebuah negeri yang tak punya raja."

\section{Fragmen Kedua}

Aku akan (mencoba) mencintaimu, monyet tua, karena engkau adalah lelaki yang memalsukan diri.

(Entah mengapa) Kudengar kesedihanmu. Tapi juga aku tahu apa yang $\mathrm{ka}(\mathrm{m}) \mathrm{u}$ percayai. Telah $\mathrm{ka}(\mathrm{m}) \mathrm{u}$ katakan, kepada senja yang hujan: "Aku Kapi Jembawan yang tak akan berakhir; aku (mampu) mengubah (semuanya), aku seperti curah air; aku mungkin (pohon) trembesi yang tak ditakdirkan (semesta)."

Saat itu langit pasti mendengar (gemuruh), seperti bumi mendengar derum guruh (saat hujan).

Jangan takut. Meskipun $\mathrm{ka}(\mathrm{m}) \mathrm{u}$ tahu: pada tiap datang gelap (malam) dan nyanyian katak dari semak yang tergenang, aku memang inginkan dengus (napas) seorang pangeran yang telah bersumpah akan menolak tubuhku.

Leksmana, pangeran Ayudhya yang menang (dalam peperangan), ingin menghilang kembali ke dalam hutan.

"Aku adalah peran," bisiknya (lemah) kepadaku, "yang tak ingin ditakdirkan."

$\mathrm{Ka}(\mathrm{m}) \mathrm{u}$ tahu kita semua bisa menangis (sejadi-jadinya).

Maka sentuhkan rambutmu yang menakutkan, monyet tua, ke bibirku. Apak, kusut, kering. Tanpa (kuasa) berahi, ranjang tetap akan menutupkan selimutnya sebelum lampu padam.

Relief pada tembok (,) tetap tak akan selesai bercerita tentang seorang dewa yang melepaskan zakarnya.

Kita semua bisa menangis (sejadi-jadinya). 


\section{Fragmen Ketiga}

'Aku telah berkhianat,' kata kera merah itu (tertunduk).

'Apa yang terjadi?' tanya sang pertapa (sambil mencermati wajah Sugriwa).

"Aku tak mengerti: telah datang dua orang asing dari (kerajaan) Ayudhya yang membunuh saudara kandungku, dan (anehnya) aku memeluk mereka sebelum aku memeluk tubuh Saudaraku (yang tak berdaya), dan mereka berkata dengan suara yang tenteram (juga sungging senyum), "Ada keadilan."

'Aku takut,' sambung kera merah itu pula (memandang pertapa).

'Kita tak perlu takut kepada yang ada dan bisa jelas (pertapa mengingat sesuatu).'

Empat malam sebelumnya, dari sebelah tenggara hutan, pertapa itu mendengar jerit(an): 'Namaku Subali!'

Ia pun berjalan mendekat. Bulan hanya sebelah (malam itu). Dalam terang yang terbatas, ditemukannya genangan darah (putih) dan sehelai daun tal yang tergeletak (begitu saja).

Seekor burung pungguk memandangi dari gelap —merasa lebih mengerti tentang malam dan jejak (peristiwa) yang terhapus.

Keadilan (yang seperti apa) dan kematian (yang sunyi) begitu sederhana di semak kosong ini.

Juga sesal dan suara sedih (seorang saudara kandung). 'Aku memang ingin ia tak ada,' kata kera merah itu pula, 'tapi aku tak ingin membunuh Subali.'

'Kau tak membunuhnya, Sugriwa. Ada perang dan keinginan (besar) yang selalu bukan milik kita.'

\section{Fragmen Keempat}

Letakkan pelan kesunyianmu, Rahwana, di sisi kesunyianku. (Kulihat) Hanya ada pohon nagasari yang tumbuh hitam di sudut taman (argasoka). (Barangkali) Kota separuh hangus. Dan (tak ada pahlawan pemberani) di tahta yang kosong di dalam, jauh di dalam, ingatan telah jadi bekas.

\section{Fragmen Kelima}

Anak itu selesai meraut hiu dari (gelondongan) kayu dan melontarkannya ke danau.

Ia (menatap arus dan) tak mengatakan apa-apa, tapi ayahnya tahu, di (hasil) pahat(an) itu hikayat (sang anak) memilih arahnya sendiri.

'Dongeng adalah metamorfosa, ayah, karena kiasan berhenti dan Sita menolak perjalanan (pulang) ke Ayudhya lagi.'

'Apa yang terjadi dengan Sita?' tanya sang ayah (pura-pura tidak tahu).

'Ia terjun (dan berdiam) ke telaga mencari ikan terbang yang menentang (arus) kematian.'

'Tapi di sebuah hutan, jauh dari istana Rama yang pulih, dua pangeran piatu yang menyingkirkan diri membentuk busur bambu dan urat daging: (mereka menantang kehidupan).

"Kami Kusya dan Lawa, pembangkang yang berkabung, yang tak ingin

siapapun mati (sia-sia)."

"Tapi dalam mimpi mereka (yang kelam) mereka bunuh ayah mereka (sendiri)."

'Dengan rahang mengetam mereka berbisik, "Jangan Paduka sentuh (lagi) ibu kami: permaisuri itu telah lama (pasrah) bertopang di punggung hiu, mencari arah ikan terbang (sendirian)".

Dan dalam cerita (yang) saya (kisahkan) ini, ayah itu pun menatap cemas mata anaknya.

'Kita tak pernah mengerti Sri Rama (menentukan pilihan),' katanya. 


\section{Pembacaan Hermeneutik Puisi "Hikayat Sri Rama" Karya Goenawan Mohamad Fragmen Kesatu}

Judul pada fragmen pertama mengacu pada Kumbakarna dalam kisah Ramayana. Seorang adik Rahwana atau Dasamuka yang memiliki sifat berbeda dengan kakaknya. Dalam fragmen ini, dipaparkan ada seorang ayah yang bercerita kepada anaknya (Ayah itu bercerita tentang seorang penidur yang sakti,). Si anak mendengarkan sambil membuat mainan serupa pahatan ikan dari kayu (Anaknya hanya memahat kayu, mungkin). Kisah yang diceritakan sang ayah adalah sosok Kumbakarna yang memiliki badan besar menyerupai raksasa ("Ia bernama Kumbakarna."). Kumbakarna sangat suka tidur, walau begitu dia seorang yang sakti. Kebiasaannya bertapa, membuat Kumbakarna ditakuti lawan. Sebagai seorang adik, Kumbakarna tidak memiliki kekuasaan atas wilayah kerajaan Alengka. Sebenarnya ada pemimpin di kerajaan Alengka, tetapi bukan pemimpin sejati yang memikirkan rakyatnya. Alengka dipimpin seseorang yang hanya sibuk mencari kesenangan diri sendiri (tentang negeri yang tak punya raja.).

Sambil mendengarkan kisah tentang Kumbakarna, Si Anak memahat kayu dan menjadikannya mainan berbetuk ikan. Dengan hati-hati Si Anak mengukir kayu karena dia tidak ingin melukai kulit tangannya jika tergesagesa. Jika bagian tubuhnya terluka, dia akan menangis karena kesakitan. Si Anak takut darah yang keluar dari tubuhnya dapat membuatnya meninggal. Siapapun tidak tahu kematian akan datang dan dengan cara yang seperti apa (dan umur (ia merasa begitu) hanya pendek.).

Ayahnya terus bercerita, sambil memperhatikan anaknya yang meraut kayu. Tugasnya sebagai ayah memang berat. Harus menjaga dan terkadang mendongengkan kisah. Kali ini kisah tentang Kumbakarna yang hidup di sebuah kerajaan besar. Kumbakarna menunggu kerajaan yang ditinggalinya menjadi lebih baik. Kumbakarna akan memperhatikan nasib mendatangi Alengka. Sebelum pergi bertapa atau sebelum meninggalkan tempat tinggalnya, Kumbakarna selalu berdoa agar Alengka menjadi lebih baik dan mampu memberikan kesejahteraan kepada rakyatnya ("Aku menunggumu, Alengka, di jalan yang tak mudah,"). Kumbakarna memang bukan seorang raja, tetapi dia sangat peduli kepada rakyat Alengka.

Kumbakarna seorang pahlawan bagi rakyatnya. Dia membela tanah airnya dari musuh. Musuh yang dimaksud adalah siapa saja yang mendatangi tanahnya dan memeranginya. Kumbakarna pergi ke medan pertempuran yang jauh, meninggalkan Alengka demi membela harga diri. Kelompok yang mengganggu pasti dikalahkan. Kepergian Kumbakarna menuju medan peperangan membuat Alengka kehilangan kendali. Alengka menjadi goyah dan seolah tidak memiliki panutan ("Tak ada lagi garis depan.").

Sampai di tempat peperangan, seorang pengintai mengabarkan kepada Kumbakarna bahwa sekelompok pasukan aneh telah bersiap menyerang. Kumbakarna tidak pernah takut pada apa pun, termasuk pasukan aneh yang dikabarkan datang dari Kiskenda (ada musuh datang dari Kiskenda). Sayangnya kumbakarna tidak percaya ada tempat bernama Kiskenda.

Kumbakarna melihat ada yang tidak sesuai dengan hati nuraninya. Dia pun pergi meninggalkan medan peperangan. Hatinya menyatakan dia harus pergi (dan ia pergi ke lekuk 
bukit). Bertapa kembali di bukit yang pernah disinggahinya. Kumbakarna tidak mau ada korban. Dia pun memilih melanjutkan pertapaannya.

Sambil mendengarkan cerita ayahnya, Si Anak mulai memahat sirip ikan (Di luar cerita, anak itu meraut sirip). Dia memandang mainan buatannya dan membayangkan ikan itu bergerak-gerak di dalam sungai yang dalam. Berenang-renang di arus yang deras, sebelum akhirnya kematian datang. Ikan dipancing dan membuat ikan menggelepar-gelepar lalu mati tak berdaya.

Melihat anaknya mulai melamun, si ayah mengakhiri cerita Dia lelah dan menutup kisah Kumbakarna dengan kalimat-kalimat pamungkas. Kumbakarna tetap harus melalui banyak peristiwa yang menyulitkan. Apalagi dia tinggal di sebuah tempat yang tidak memiliki pemimpin sejati.

\section{Fragmen Kedua}

Judul fragmen dua mengacu pada kisah cinta terlarang antara bangsawan, seorang bangsa monyet, dan perempuan jelita.

Aku lirik dalam fragmen dua adalah tokoh Trijatha yang sedang berhadapan dengan Kapi Jembawan. Trijatha menerima kehadiran Kapi Jembawan dengan terpaksa karena sebuah kejadian yang tidak sesuai dengan keinginannya (/karena engkau adalah lelaki//yang memalsukan diri./).

Trijatha mengetahui perasaan

Kapi Jembawan karena dia seorang perempuan yang memiliki kepekaan. Trijatha merasakan kesedihan Kapi Jembawan dan mempercayai firasat hatinya sendiri. Saat dipenuhi kesedihan, Kapi Jembawan mengatakan isi hatinya kepada Trijatha ("Aku Kapi Jembawan yang tak akan berakhir;) dengan penuh kejujuran. Kapi Jembawan rela mengubah kebiasaan yang dimilikinya, rela menjadi tempat singgah seperti pohon-pohon yang mampu meneduhi (aku mungkin trembesi).

Pernyataan-pernyataan yang diucapkan Kapi Jembawan didengar bumi dan langit. Alam semesta seolah menyetujui ucapan Kapi Jembawan (Saat itu langit pasti mendengar,) dan merestui tindakan yang akan dilakukan Kapi Jembawan.

Berbeda dengan kehendak semesta, Trijatha tidak menginginkan kehadiran Kapi Jembawan. Setiap malam, Trijatha melamunkan nasib hidupnya. Trijatha menginginkan pendamping hidup seorang pangeran, tetapi keinginan itu tidak pernah didapatkannya (aku memang inginkan dengus seorang pangeran). Karena suatu peristiwa yang tidak diketahui Trijatha, pangeran pernah mengucapkan sebuah sumpah.

Pangeran itu bernama Leksmana, seorang bangsawan yang berasal dari Ayudhya (Leksmana, pangeran Ayudhya yang menang,). Pangeran perkasa yang sering memenangkan peperangan. Laki-laki yang hidup di hutan untuk waktu lama.

Trijatha masih berhadapan dengan Kapi Jembawan. Seorang perempuan yang tidak mampu menolak karena hidupnya memang telah ditakdirkan bersanding dengan keturunan kera. Kapi Jembawan masih berusaha meyakinkan Trijatha ("Aku adalah peran," bisiknya kepadaku,).

Trijatha pasrah. Dia akan menjalani kehidupan bersama Kapi Jembawan. Trijatha bersedih hati, namun tidak mampu berbuat apa-apa (Kau tahu kita semua bisa menangis.).

Trijatha menerima kehadiran Kapi Jembawan. Kehidupan berkeluarga yang selama ini sudah dibayangkan bersama seorang pangeran. Dengan ragu-ragu Trijatha menerima 
cinta Kapi Jembawan dengan perasaan hampa (Tanpa berahi, ranjang tetap). Dia masih saja tidak percaya ada seorang pangeran yang melepaskan alat kelaminnya. Alat vital bagi seorang laki-laki yang berfungsi untuk melanjutkan keturunan (yang melepaskan zakarnya).

Trijatha mengetahui dirinya akan terus bersedih sepanjang hidup. Dia juga tahu Leksmana dan Kapi Jembawan memiliki kesedihan masingmasing. Rasa cinta Trijatha kepada Leksmana tidak dapat diwujudkan. Rasa cinta Kapi Jembawan kepada Trijatha hanya berlangsung searah walau mereka hidup bersama. Sementara itu Leksmana memilih hidup di tengah kesunyian (ingin menghilang kembali ke dalam hutan.).

\section{Fragmen Ketiga}

Puisi pada bagian fragmen tiga berisi percakapan antara Sugriwa dan seorang pertapa ('Apa yang terjadi?' tanya sang pertapa.). Sugriwa lahir sebagai bangsa kera. Dia Memiliki kakak kandung bernama Subali. Kakak adik tersebut hidup dalam sebuah kerajaan dengan Sang Kakak yang memimpin kerajaan. Karena sebuah peristiwa, kakak adik tersebut berubah haluan. Perbedaan membuat hubungan persaudaraan berubah menjadi musuh.

Permusuhan

tersebut

dimanfaatkan oleh tamu yang datang dari kerajaan Ayudhya. Dua pangeran yang tak lain Sri Rama dan Laksmana datang ke Kiskenda dengan sebuah alasan. Mereka sedang membutuhkan bantuan prajurit kera untuk membantu menyelamatkan Sita yang diculik Rahwana (nama lain Prabu Dasamuka). Akhirnya mereka bersepakat bahwa prajurit kera akan membantu pencarian Sita.

Si Pertapa menceritakan bahwa empat hari sebelumnya dia mendengar jeritan seseorang. Jeritan itu menyebutkan sebuah nama ('Namaku Subali!'). Dia penasaran dengan apa yang terjadi. Sayangnya Si Pertapa hanya menemukan genangan darah putih dan daun-daun berserakan seolah baru terjadi perkelahian. Si Pertapa mendengar suara burung hantu (Seekor burung pungguk). Barangkali burung itu melihat apa yang baru saja terjadi. Sayangnya $\mathrm{Si}$ Pertapa tidak dapat memahami bahasa burung hantu.

Si Pertapa hanya menemukan hutan yang sunyi dan perasaan aneh dari dalam hatinya. Sebagai seorang yang sedang melepaskan nafsu duniawi, Si Pertapa tahu ada peristiwa besar yang akan menuntunnya bertemu seseorang.

Firasat Si Pertapa terbukti, beberapa hari selanjutnya dirinya bertemu Sugriwa yang tak lain adalah adik Subali. Mereka berdua bercakap dan mendapatkan kesedihan di wajah Sugriwa. Si Pertapa menasihati kera merah yang ada di hadapannya. Kebenaran akan selalu dimenangkan dan alam semesta akan memperlihatkan segala kebenaran. Dengan rasa sedih, Sugriwa menerima kepergian kakaknya.

\section{Fragmen Keempat}

Bagian ini berisi kisah penculikan Sita yang dilakukan Rahwana. Sita diculik ketika berada di hutan. Saat itu Sita sedang menemani masa hukuman yang dijalankan suaminya, Ramawijaya. Ketika Ramawijaya sedang berburu, Rahwana mengubah diri menjadi resi tua peminta-minta. Sita yang welas asih memberikan makanan kepada Rahwana yang sedang menyamar. Pada saat itulah Sita diculik.

Sita dibawa ke kerajaan Alengka tempat Rahwana berkuasa. Di Alengka Sita ditempatkan di taman Argasoka. Sita senantiasa menjaga diri dan menjaga kesuciannya. Sehari-hari Sita 
berteman sunyi karena dia tidak mau bertemu siapa pun termasuk Rahwana. Di taman yang sangat indah tersebut, kebutuhan Sita dipenuhi. Dia tidak pernah kelaparan dan dapat melakukan apa saja.

Hingga pada suatu hari, datang suruhan Ramawijaya untuk mencari kabar Sita. Suruhan itu mengobrakabrik tempat Sita ditawan dan membakar taman hingga pusat kota kerajaan Alenka. Setelah mengacakngacak wilayah kekuasaan Alengka, Suruhan itu pergi. Sita melihat kehancuran taman yang awalnya indah. Saat itu Sita merasakan kesunyian yang sangat dalam. Sita tidak tahu harus mencurahkan isi hatinya kepada siapa, kegundahan sebagai perempuan tawanan dan ingatan akan suaminya.

\section{Fragmen Kelima}

Judul terakhir adalah klimaks dari seluruh rangkaian fragmen. "Epilog" berarti penutup, juga berarti peristiwa terakhir yang menyelesaikan peristiwa induk. Bait pertama dalam fragmen lima berkait dengan bait ketiga pada fragmen pertama.

Seorang anak telah selesai membuat pahatan ikan dari kayu. Anak itu ingin mencoba hasil karya dengan cara melemparkannya ke danau. Anak itu memperhatikan ikan buatannya dari tepi danau.

Sementara ayah Si Anak hanya diam saja. Dia tidak berkomentar dengan karya anaknya. Si Ayah seolah tahu nasib anaknya hanya dengan melihat ikan yang sedang mengambang di hadapannya.

Tiba-tiba si anak melanjutkan kisah Sita. Katanya, Sita tak mau pulang ke Ayudha. Si Ayah kaget dengan ucapan anaknya. Dari mana anaknya tahu kelanjutan kisah, sementara dirinya belum bercerita. Si Ayah pura-pura tidak tahu, dia memutuskan mendengarkan anaknya berkisah.

Sita kecewa kepada Rama. Sita pun terjun ke telaga api yang menjilatjilat. Sita yang tidak pernah takut apa pun, seolah menentang kematian. Di dalam api suci, Sita ingin membuktikan kepada suaminya, Ramawijaya, bahwa dirinya seorang istri yang baik. Mampu menjaga semua tanggung jawab yang diberikan. Hingga akhirnya telaga api itu padam dan menyisakan Sita yang bersinar. Sita mampu membuktikan keraguan Rama. Sita yang kecewa pada suaminya memutuskan pergi.

Di tempat yang baru, Sita membesarkan kedua anaknya bernama Kusya dan Lawa. Ramawijaya mengira kedua anak itu adalah benih Rahwana (fragmen empat). Namun, keberhasilan upacara bakar diri yang dilakukan Sita menjawab keraguan Ramawijaya. Sayangnya, tindakan Ramawijaya yang mencurigai istrinya menumbuhkan dendam di dada Kusya dan Lawa. Kedua anak itu ingin membalaskan sakit hati ibunya.

Mereka sedih jika mengingat perlakuan ayah mereka kepada Sita. Kesedihan itu terbawa sampai mimpi. Di dalam tidur, Kusya dan Lawa membunuh Ramawijaya. Mengancam ayah mereka untuk tidak berdekatan dengan Sita. Ibu mereka telah menjadi perempuan suci dan tidak memiliki dosa apa-apa.

Sang Ayah masih mendengarkan anaknya berkisah. Tiba-tiba dia khawatir dengan kemampuan yang dimiliki anaknya. Khawatir nasib buruk menimpa anaknya, seperti nasib buruk yang menimpa Sita. Sang Ayah tidak tahu takdir anaknya di masa depan, seperti dia tidak mengerti dengan keputusan Rama terhadap Sita.

\section{Makna Puisi "Hikayat Sri Rama" Karya Goenawan Mohamad}


Salah satu makna yang terdapat dalam puisi "Hikayat Sri Rama" berhubungan dengan zaman modern ini adalah hubungan anak dan orangtua. Pengasuhan atau pengawasan anak sudah tidak lagi dilakukan ayah atau ibu karena sibuk bekerja. Seringkali pengasuhan digantikan orang lain, sehingga hubungan anak dan orangtua berjarak. Ayah atau ibu tidak lagi mengetahui sifat atau kesukaan si anak. Melalui puisi ini, masyarakat diingatkan kembali pentingnya pengasuhan orangtua. Salah satunya menggunakan media bercerita. Nasihat-nasihat dari orangtua akan lebih mudah diserap melalui perantara cerita, misalnya menggunakan kisah pewayangan seperti yang dilakukan tokoh ayah dalam puisi ini.

\section{Pembacaan Heuristik Puisi "Penyesalan Kunti" Karya Djoko Saryono}

Risau tiba di dada ketika Kunti (sendirian) dirajam duri-duri sepi. Cekam kuat ingatan pada (nama) Basukarna tak (pernah) sudi pergi: mengiris-iris pipih serpih(an) hati (yang sakit).

"Duh Gusti kang murbeng dumadi (,) kenapa mantra aji pepanggil* (itu)

kucoba semau sendiri (,) tak hati-hati hingga terjadi kehamilan (yang) tak kuingini (,) padahal aku tak sudi tubuh terlukai, (ia) harus tetap suci (,) keperawanan tetap kumiliki selepas kelahiran bayi (yang tak kuduga.) tak (ada yang) boleh tahu (,) seorang lelaki, bahkan seisi bumi (ini.) sebelum terang meminang pagi, (lalu) melamar matahari(.)"

[Dan Batara Surya (mem)bantu (me)lahirkan bayi lewat telinga (,) maka ia bernama Basukarna, putra mentari di dunia (fana,) ia tak pernah merasai keindahan gua garba (milik) ibunda(.)]
"Duh Gusti kang murbeng dumadi (,) anakku Basukarna terpaksa kularung

di kali (,) kupisahkan dari belas kasih ibu kandung sejati karena gemerlap (dunia) citra wanita istana lebih kuikuti (,) karena kilap status terpandang mesti lebih kuimani ketimbang tanggung jawab pada perbuatan tak terpuji (dahulu kala,) karena kesempurnaan palsu lebih kuimami (,) karena kepura-puraan suci mesti kulindungi ketimbang mengakui Basukarna (sebagai) anak kandung sendiri (,)" sesal Kunti dituntun jernih budi ketika (ke)sadar(an) merambati(.)

"Duh Gusti kang murbeng dumadi (,) Basukarna berjalan dari kehinaan ke kehinaan bumi (berikutnya,) karena segenap terang telah kusembunyikan di (dalam) hati dan kututupi gengsi sebagai wanita muda idaman lelaki(.) apakah aku ibu (kandung yang) tak punya sanubari dan lancung pekerti?

"Duh Gusti kang murbeng dumadi (,) memang aku tak sedahsyat, tak sehebat Satyawati (yang) berani mengakui Abiyasa anak kandung sendiri ketika kekalutan dinasti mengirim segenap jeri (,) (se)hingga keutuhan negeri terlindungi, tegak berdiri (sampai kini)", leluhur Astina nan luar biasa dikagumi Kunti(.)

Risau jiwa telah pulang ke desah dada(.) Ingatan pada Basukarna (semakin) lekat di syaraf kepala(.) Kunti terpana: "kegelapan selalu menuntut dibuka (paksa)!” Kunti ternganga: "jalan hidup sungguh susah diterka!"

\section{Pembacaan Hermeneutik Puisi "Penyesalan Kunti" Karya Djoko Saryono \\ Pada masa remaja, Kunti mendapatkan anugerah dari Batara Surya. Dia diberikan mantra atau doa bernama aji pepanggil. Batara Surya}


menjanjikan bahwa jika Kunti membacakan mantra tersebut dia akan mendapatkan anugerah menjadi seorang ibu.

Kunti bermain-main membacakan mantra aji pepanggil. Dia belum benar-benar mengerti apa yang harus dilakukan jika sesuatu terjadi pada dirinya (kenapa mantra aji pepanggil* kucoba semau sendiri). Tetapi apa daya, mantra terlanjur dibaca oleh Kunti dan dia mendapatkan anugerah seorang anak. Seiring berjalannya waktu, Kunti menyembunyikan anak yang terdapat di rahimnya. Saat waktunya persalinan, Kunti dibantu Batara Surya mengeluarkan calon anak manusia melalui telinga.

Kunti menghanyutkan anaknya yang diberi nama Basukarna ke sungai (anakku Basukarna terpaksa kularung di kali). Dia benar-benar belum siap menjadi ibu. Semua hal yang dialaminya harus dirahasiakan karena Kunti akan menjadi seorang istri dari salah satu pangeran muda kerajaan Astina. Kunti lebih memilih kedudukan dan kehidupan yang enak di istana. Dia harus melupakan anak keturuan dewa yang dibuangnya.

Tahun-tahun berlalu dan Kunti menyadari kesalahannya (Risau jiwa telah pulang ke desah dada). Dia menyesali perbuatan yang telah dilakukannya pada masa remaja. Kini hanya ada kesedihan dan kegelisahan yang mengurung Kunti pada masa tua. Dia menyadari dirinya bukanlah seorang ibu yang baik. Kunti membayangkan anaknya mencari-cari dirinya. Basukarna pasti menderita karena tidak pernah merasakan kasih sayang ibu kandungnya (Basukarna berjalan dari kehinaan ke kehinaan bumi). Seharusnya dia mencontoh Satyawati yang berani mengakui keberadaan anak kandungnya kepada rakyat Astina.

Kunti hanya bisa mengharap belas pengampunan Yang Maha Kuasa ("Duh Gusti kang murbeng dumadi). Kunti hanya bisa meratap dan menyesali apa yang telah diperbuatnya. Tidak ada yang dapat dilakukannya karena waktu tidak dapat diputar ulang. Takdir hidup menjadikan Kunti seorang ibu yang tidak sempurna dan dia ingin membenahi hidupnya (Kunti terpana: “kegelapan selalu menuntut dibuka!").

\section{Makna Puisi "Penyesalan Kunti" Karya Djoko Saryono}

Setiap manusia dianugerahi kemampuan berpikir dan seharusnya mampu memaksimalkan kelebihan itu. Sebelum melakukan suatu hal, sebaiknya dipikirkan matang-matang, sehingga tidak menyesal pada kemudian hari. Puisi "Penyesalan Kunti" berusaha mengingatkan kembali pembaca untuk tidak melakukan hal-hal yang sia-sia. Lima ajaran pokok tentang kebenaran yang terdapat dalam kisah pewayangan menurut Kresna (2012) adalah menembah (menyembah kepada Tuhan yang Maha Esa), menepi (sabar, introspeksi diri, dan menghindari pertengkaran), maguru (berguru mencari ilmu pengtahuan), mangabdi (mengabdi kepada keluarga, masyarakat, bangsa dan negara serta agama), dan makarya (bekerja tanpa pamrih untuk mencukupi kebutuhan dan mencapai kesejahteraan). Puisi "Penyesalan Kunti" dapat merujuk pada ajaran menepi atau intropeksi diri.

Jika dihubungkan dengan masa kini, berseliweran berita-berita bohong yang dapat dengan mudah diakses. Sebagai individu seharusnya berpikir dahulu sebelum ikut menyebarkan dengan cara mengecek kebenaran terlebih dahulu. Tokoh Kunti dalam teks puisi adalah perempuan yang 
menyesal karena telah bermain-main dengan mantra pemberian dewa menjadi metafor keadaan saat ini.

\section{SIMPULAN}

Pembacaan heuristik dan pembacaan hermeneutik merupakan dua tahap pembacaan yang mengarahkan pada keterkaitan teks puisi dengan teks pendahulunya (kisah pewayangan). Terdapat perkembangan teks puisi yang merujuk pada perubahan zaman. Teks puisi atau yang dapat disebut teks tranformasi menyerap perubahan waktu dan berdampak pada tindakan-tindakan tokoh kisah pewayangan dalam teks puisi.

Usaha yang dilakukan penyairpenyair Indonesia, di antaranya: Sapardi Djoko Damono, Goenawan Mohamad, dan Djoko Saryono mendatangkan harapan baru bahwa budaya bangsa tidak akan hilang tergerus zaman yang terus mengarah ke era digital. Kehadiran puisi berdasarkan kisah pewayangan Jawa, menjadi langkah strategis agar masyarakat luas mengenali budaya adiluhung. Kisah pewayangan sebagai warisan bangsa memiliki nilai-nilai humanis dan menjadi pondasi kuat agar tidak terjadi gegar budaya pada generasi muda.

\section{DAFTAR PUSTAKA}

Damono, S. D. (2004). Hujan Bulan Juni. Jakarta: Grasindo.

Begini $\begin{gathered}\text { Maksudnya } \\ \text { Jakarta: Gramedia. }\end{gathered}$
Begitu.

Danardana, A. S. (2013). Pelangi Sastra: Ulasan Dan ModelModel Apresiasi. Pekanbaru: Palagan Press.
Endraswara, S. (2013). Metodologi Penelitian Sastra. Yogyakarta: CAPS.

Kresna, A. (2012). Mengenal Wayang. Yogyakarta: Laksana.

Mahmud, A. (2011). Tema Puisi Indonesia Modern Periode Awal. Atavisme, 14 (1), hlm. 41-50.

Mohamad, G. (2013). Gandari. Jakarta: Tempo.

Moleong, L. J. (2014). Metodologi Penelitian Kualitatif: Edisi Revisi. Bandung: Rosda.

Nurgiyantoro, B. (1998). Transformasi Unsur Pewayangan Dalam Fiksi Indonesia. Yogyakarta: Gadjah Mada University Press.

Nurgiyantoro, B. (2003). "Wayang dalam Fiksi Indonesia". Humaniora, 15 (1), hlm. 1-14.

Ra'uf, A. (2010). Jagad Wayang: Epos Pintar Yang Membuat Anda Melek Kearifan Tradisi Dan Sejarah. Jogyakarta: Garailmu.

Ratih, Rina. (2016). Teori dan Aplikasi Semiotik Michael Riffaterre. Yogyakarta: Pustaka Pelajar.

Ratna, N. K. (2010). Sastra dan Cultural Studies: Representasi Fiksi dan Fakta. Yogyakarta: Pustaka Pelajar.

Saryono, D. (2013). Arung Diri. Malang: Aditya Media Publishing.

Sugiyono. (2014). Metode Penelitian Kombinasi (Mixed Methods). Bandung: Alfabeta. 
Teeuw, A. (1980). Sastra Baru Indonesia Modern I. Ende: Nusa Indah.

(1989). Sastra Indonesia Modern II. Jakarta: Pustaka Jaya.
Tim Penulis Sena Wangi. (1999). Ensiklopedi Wayang Indonesia. Jakarta: Sena Wangi.

Zaidan, A. R. dkk. (2002). Mitologi Jawa Dalam Puisi Indonesia 1971-1990. Jakarta: Pusat Bahasa Departemen Pendidikan Nasional. 